\title{
ANÁLISE DO CAPITAL SOCIAL DA AGRICULTURA NO MUNICÍPIO DE PENTECOSTE (CE)
}

\author{
ANALYSIS OF SOCIAL CAPITAL OF AGRICULTURE IN THE MUNICIPALITY \\ PENTECOSTE (CE)
}

\author{
Gerlânia Maria Rocha Sousa ${ }^{1}$ \\ Guillermo Gamarra Rojas ${ }^{2}$ \\ Emanoel Márcio Nunes ${ }^{3}$ \\ José Newton Pires Reis ${ }^{4}$ \\ José Alex do Nascimento Bento ${ }^{5}$
}

\begin{abstract}
RESUMO
O presente trabalho tem como objetivo analisar o nível de capital social da agricultura do município de Pentecoste (CE). Para a obtenção dos dados foram aplicados questionários com questões sobre o tema proposto em 42 comunidades rurais do município que corresponde a 163 famílias. O tratamento analítico dos dados consistiu na aplicação da técnica de análise multivariada conhecida como análise fatorial. A partir dessa técnica construiu-se o Índice de Capital Social para as comunidades rurais do município e, adicionalmente, na identificação e classificação das comunidades em clusters, de acordo com a mensuração do capital social nessas comunidades através da análise de agrupamento ou cluster. Com isso, foi feito inicialmente análise do índice que se acredita ser capaz de dar uma ideia a respeito do nível de capital social de acordo com as categorias: grupos e redes, confiança e solidariedade, ação coletiva e cooperação, coesão inclusão social e políticas públicas e assistência técnica. Em seguida, aplicou-se a análise de agrupamento ou cluster para agrupar esse índice em categorias de ordem baixa, média e alta. O ICS proposto mostrou um nível médio de capital social e uma deficiência em relação às variáveis estudadas.
\end{abstract}

Palavras-chave: Capital Social. Políticas Públicas. Organizações.

\section{ABSTRACT}

This study aims to analyze the level of capital of Pentecost county agriculture (CE). To obtain the data were questionnaires with questions about the proposed topic in 42 rural communities in the municipality corresponding to 163 families. The analytical data processing consisted in the application of multivariate analysis technique known as factor analysis and from the application of this technique has built up the Social Capital Index for rural communities in the municipality and additionally in the identification and classification of

\footnotetext{
${ }^{1}$ Mestre em Economia Rural pela Universidade Federal do Ceará (UFC). E-mail: gerlaniarocha@gmail.com

2 Doutor em Botânica pela Universidade Federal Rural de Pernambuco (UFRPE). Professor Adjunto da Universidade Federal do Ceará(UFC). E-mail: ggamarra@terra.com.br

${ }^{3}$ Doutor em Desenvolvimento Rural pela Universidade Federal do Rio Grande do Sul (UFRGS). Professor Adjunto IV do Departamento de Economia da Universidade do Estado do Rio Grande do Norte (UERN). E-mail: emanuelnunes@uern.br

${ }^{4}$ Doutor em Economia Aplicada pela Universidade de São Paulo (USP). Professor Associado IV da Universidade Federal do Ceará (UFC). E-mail: newton@ufc.br

${ }^{5}$ Mestrando em Economia Rural pela Universidade Federal do Ceará (UFC). E-mail: josealex@yahoo.com.br
}

Revista de Estdudos Sociais |Ano 2015 N.34. V.17 
communities in clusters, according to the measurement of social capital in these communities through cluster analysis or cluster. Thus, it was initially done the analysis of the index that is believed to be able to give an idea about the level of social capital according to the categories: groups and networks, trust and solidarity, collective action and cooperation, cohesion and social inclusion policies public and technical assistance. Then applied to cluster analysis to group or cluster that index in low-order categories, medium and high. The proposed ICS showed an average level of social capital and a deficiency in relation to the variables studied.

Keywords: Social Capital. Public Policy. Organizations.

JEL: 018

\section{INTRODUÇÃO}

Ao longo dos anos o debate e as discussões em torno da agricultura familiar vêm se intensificando principalmente no âmbito das dinâmicas de desenvolvimento. No entanto, a agricultura familiar, principalmente no Brasil, sempre foi considerada por defensores da modernização agrícola um segmento atrasado, de pouco interesse econômico para a sociedade e menor significância analítica para a academia.

Segundo a FAO/INCRA (2000), a mesma consiste na gestão da produção e investimentos, exercida principalmente por trabalhadores com grau de parentesco, a qual pressupõe a distribuição igualitária da operacionalização da produção.

A temática sobre desenvolvimento no Brasil se desenvolveu com mais intensidade a partir dos anos 1990. Para Abramovay (2007), essa década, iniciada com a entrada da agricultura familiar no vocabulário científico é a década atual de uma reavaliação do significado de desenvolvimento rural, pois aborda as dinâmicas territoriais no processo desenvolvimentista.

Atualmente, o capital social tem sido estudado como uma nova abordagem explicativa centrada no desenvolvimento. A estagnação dos modelos de desenvolvimento, com ênfase no crescimento contínuo do produto nacional ou "per capita", demonstra sua insustentabilidade face às distorções econômicas, sociais, culturais e ambientais produzidas (BARRETO, 2004).

O capital social vem adquirindo maior embasamento, revigorando-se com o objetivo de se tornar de fato consolidado e sustentável devido à existência de uma grande subjetividade em torno do próprio capital social. No entendimento de Andrade \& Cândido (2008), apesar das limitações teóricas e metodológicas, este conceito se constitui como um importante elo no processo de revitalização da democracia, fomentando a construção de uma identidade coletiva e, consequentemente, interferindo na maior compreensão e resolução dos dilemas atuais.

Dentre os municípios pertencentes ao Território da Cidadania Vales do Curu e Aracatiaçu no estado do Ceará, destaca-se o município de Pentecoste, pertencente ao Micro Território Médio Curu, que é localizado no norte do estado do Ceará e que caracterizado por uma vasta população rural e atividade fortemente agrícolas. Tanto nesse território como no município de 
Pentecoste existem organizações formais e não formais, fóruns, conselhos e outras instâncias de deliberação e/ou decisão que são sinais positivos de desenvolvimento do capital social.

Assim, devido às transformações no espaço rural verificadas nos últimos anos e a evolução do conceito de capital social frente às relações sociais nas comunidades, fez necessário à criação de políticas e/ou programas, projetos, organizações e instituições para o desenvolvimento da agricultura. As questões de desenvolvimento territorial com suas políticas de incentivo à diversificação da produção e organização dos agricultores em forma de organizações ganharam importância e necessidade de serem analisadas pelo nível do capital social nesse município. Dessa forma, é preciso entender como o capital social atua na agricultura e como se relaciona, demonstrando sua necessidade e fragilidade.

O tratamento analítico consiste na construção de um índice do capital social (ICS) a partir da aplicação de técnica de análise multivariada conhecida por análise fatorial e, adicionalmente, na identificação e classificação das comunidades rurais estudadas em clusters, de acordo com a mensuração do capital social.

\section{REFERENCIAL TEÓRICO}

\subsection{Capital Social: Uma abordagem conceitual}

Conforme Sachs \& Lages (2001), a expressão "capital social" procura dar significado à importância da presença e da qualidade das relações sociais para o desencadeamento do processo de desenvolvimento. Deste modo, refere-se às relações que os indivíduos desenvolvem mutuamente.

Antes de apresentar algumas definições referentes ao capital social é possível traçar três principais origens desse conceito. A primeira limita-se aos escritos de autores provenientes das ciências sociais que evidenciaram e difundiram expressamente o termo, destaque para Pierre Bourdieu, James Coleman e Robert Putnam. A segunda trata de certos elementos como confiança, coesão social, redes, normas e instituições, em vários contextos e disciplinas. A terceira mais extensa inclui autores cuja produção contém elementos precursores do conceito de capital social - remonta à sociologia clássica do século XIX, incluindo autores como Émile Durkheim e Max Weber (ALBAGLI \& MACIEL, 2002). Seguem abaixo algumas contribuições referentes à linha de pensamento do primeiro conjunto de autores que são de fundamental importância para a formação teórica do presente trabalho em relação a esse tema.

Segundo Albagli \& Maciel (2002), esses autores definem capital social a partir de sua funcionalidade e considerando uma variedade de relações presentes na estrutura social que facilita as ações dos indivíduos. Ademais, segundo os autores, Bourdieu usou o termo "Capital Social", pela primeira vez, no início da década de 1980, para se referir às vantagens e às oportunidades de se pertencer a certas comunidades e definiu esse termo como o agregado de recursos reais ou potenciais que estão ligados à participação em uma rede durável de relações mais ou menos institucionalizadas de mútua familiaridade e reconhecimento que provê para cada um de seus membros o suporte do capital de propriedade coletiva. (BOURDIEU, 1980) 
Ainda segundo aqueles autores, Coleman procurou unir a abordagem sociológica com a econômica e dentre seus vários estudos e definições em relação ao tema, é importante destacar que o mesmo especifica três formas de capital social. A primeira lida com o nível de confiança e a real extensão das obrigações existentes a um ambiente social. O capital social é elevado em que as pessoas confiam umas nas outras e essa confiança é exercida pela aceitação mútua de obrigações. A segunda diz respeito aos canais de trocas de informações e ideias. Na terceira forma, normas e sanções constituem capital social em que elas encorajam os indivíduos a trabalharem por um bem comum, abandonando interesses próprios imediatos (COLEMAN, 1990 apud ALBAGLI \& MACIEL, 2002).

Conforme Long (2007), a questão da agência humana é central nesse debate. É a maneira como os atores locais aplicam os programas de desenvolvimento, mediante práticas discursivas e organizadoras, manipulam certos elementos restritivos a um esforço para envolver os outros indivíduos em seus projetos. A capacidade desses atores de estabelecer relações organizadas (mercantis e não mercantis) é o que favorece não só a troca de informações e a conquista mútua de certos mercados, mas também pela existência de bens públicos e de administrações capazes de promover a dinamização regional, sendo possível criar capital social onde não existe. (ABRAMOVAY, 1998; ALBUQUERQUE \& CÂNDIDO, 2011).

$\mathrm{Na}$ visão de Beduchi Filho \& Abramovay (2004), a depender da capacidade criadora que a própria interação entre atores locais é capaz de conduzir, pode-se substituir as estruturas sócio-políticas piramidais por uma abordagem policêntrica com múltiplas instâncias de decisão em relação ao destino dos territórios, que incorpora as dimensões econômica, ambiental, social e cultural. Já para Putnam (1993), capital social é tido como traços da vida social - redes, normas e confiança - que facilitam a ação e a cooperação na busca de objetivos comuns.

A abordagem acerca do capital social associada a Putnam se refere à natureza e à extensão do envolvimento de um indivíduo em várias redes informais e organizações cívicas formais. Desde a conversa com os vizinhos ou o engajamento em atividades recreativas, até a filiação a organizações ambientais e a partidos políticos, o capital social é usado como um termo conceitual que caracteriza as muitas e variadas maneiras pelas quais os membros de uma comunidade interagem (GROOTAERT et al., 2003).

Em suma, os principais autores apresentados que tratam sobre a lógica do capital social, debatem a eficiência das redes de relações sociais e das normas sociais como guias de ação para o indivíduo, que também são construídas ou reforçadas pelos próprios indivíduos ou de maneira coletiva. A confiança é enfatizada, além da coesão social, participação, as quais geram conexões e redes, refletindo assim no desenvolvimento socioeconômico e aperfeiçoamento institucional.

\section{ASPECTOS METODOLÓGICOS}

\subsection{Origem dos Dados e Tamanho da Amostra}


Os dados e informações empregados no estudo foram de origem primária e o período da coleta é ano de 2014. Os mesmos foram obtidos através da aplicação de questionário semiestruturado junto a 163 famílias de agricultores familiares de 42 comunidades rurais do município de Pentecoste (CE).

A pesquisa foi realizada através de um processo de amostragem não probabilística por conveniência, levando em conta a população existente nas comunidades em análise. Nos métodos de amostragem não probabilística, as amostras são obtidas de forma não aleatória, ou seja, a probabilidade de cada elemento da população de fazer parte da amostra não é igual e, portanto, as amostras selecionadas não são igualmente prováveis (FÁVERO, 2009). O método por conveniência pode ser aplicado quando a participação é voluntária ou os elementos da amostra são escolhidos por uma questão de conveniência ou simplicidade.

\subsection{Seleção de Indicadores e Tratamento dos Dados}

Dada a complexidade dos estudos a respeito do capital social e os vários tipos de indicadores existentes, optou-se por abordar esta questão a partir de quatro dimensões propostas por Grootaert et al. (2003) e uma quinta dimensão elaborada no presente trabalho como uma forma de complementar para enriquecer a análise. Através dessas dimensões pode-se criar um conjunto de questões essenciais para medir os níveis do capital social. As dimensões citadas abaixo foram adaptadas ao contexto de estudo no qual abrange o capital social no âmbito da agricultura:

- Grupos e Redes: esta é a categoria mais comumente associada ao capital social. Considera-se a natureza e a extensão da participação de um membro de um domicílio em vários tipos de organização social e redes informais, assim como as várias contribuições dadas e recebidas nestas relações.

- Confiança e Solidariedade: esta categoria busca levantar dados sobre a confiança em relação a vizinhos, dirigentes das formas de organizações e governantes locais e regionais.

- Ação Coletiva e Cooperação: esta categoria investiga se e como os membros do domicílio têm trabalhado com outras pessoas em sua comunidade e em projetos comuns.

- Coesão e Inclusão Social: as "comunidades" não são entidades coesas, mas antes se caracterizam por várias formas de divisão e diferenças que podem levar ao conflito. Questões nesta categoria buscam identificar a natureza e o tamanho dessas diferenças, os mecanismos por meio dos quais elas são gerenciadas, e quais os grupos que são excluídos dos serviços públicos essenciais. Questões relativas às formas cotidianas de interação social também são consideradas.

- Políticas Públicas e Assistência Técnica: essa categoria foi incluída por retratar questões relacionadas às políticas públicas as quais os membros da comunidade têm acesso, a presença ou não de assistência técnica e se existe adequada infraestrutura. O Quadro 1 apresenta a definição das variáveis utilizadas para a construção do Índice de Capital Social (ICS). Os dados utilizados são de natureza primária. 


\section{Quadro 1 - Dimensões e Indicadores do ICS}

\begin{tabular}{|c|c|}
\hline DIMENSÕES & INDICADORES/VARIÁVEIS \\
\hline \multirow{4}{*}{ Grupos e Redes } & Participação em alguma forma de organização \\
\hline & Forma de organização na qual participa \\
\hline & Tipo de organização na qual participa (local ou regional) \\
\hline & Frequência na qual participa da forma de organização \\
\hline \multirow{3}{*}{$\begin{array}{l}\text { Confiança e } \\
\text { Solidariedade }\end{array}$} & $\begin{array}{l}\text { Nível de confiança em relação aos dirigentes da forma de organização na qual } \\
\text { participa }\end{array}$ \\
\hline & Nível de confiança em relação aos governantes locais \\
\hline & Nível de relacionamento com os vizinhos da comunidade onde reside \\
\hline \multirow{3}{*}{$\begin{array}{l}\text { Ação Coletiva e } \\
\text { Cooperação }\end{array}$} & Participação em alguma atividade voluntária de cunho local ou regional \\
\hline & $\begin{array}{l}\text { Existência de interação na comunidade a fim de solicitar ações de } \\
\text { desenvolvimento local }\end{array}$ \\
\hline & $\begin{array}{l}\text { Participação nas decisões a serem tomadas para o desenvolvimento da } \\
\text { comunidade }\end{array}$ \\
\hline \multirow{3}{*}{$\begin{array}{l}\text { Coesão e Inclusão } \\
\text { Social }\end{array}$} & $\begin{array}{l}\text { Existência de problemas na comunidade quanto às diferenças raciais, sociais, } \\
\text { culturais, políticas, religiosas }\end{array}$ \\
\hline & $\begin{array}{l}\text { Envolvimento da família em algum problema de cunho racial, social, cultural, } \\
\text { político, religioso existentes na comunidade }\end{array}$ \\
\hline & Existência de problemas em relação à violência na comunidade \\
\hline \multirow{4}{*}{$\begin{array}{l}\text { Políticas Públicas } \\
\text { e Assistência } \\
\text { Técnica }\end{array}$} & $\begin{array}{l}\text { Existência de políticas ou programas envolvidos na geração de } \\
\text { desenvolvimento local na comunidade }\end{array}$ \\
\hline & Participação em algumas dessas políticas ou programas \\
\hline & Existência de assistência técnica para a agricultura \\
\hline & Frequência da assistência técnica \\
\hline
\end{tabular}

Fonte: Elaborado pelos autores.

\subsection{Métodos de Análise}

\subsubsection{Análise Descritiva}

A técnica da análise descritiva foi empregada com o objetivo de caracterizar o capital social de acordo com as políticas, os programas, os projetos, as formas de organizações e as instituições de acesso aos agricultores das comunidades em estudo. Foram utilizadas tabelas de distribuição de frequências (absoluta e relativa) e as medidas de tendência central. A pesquisa descritiva tem como objetivo primordial a descrição das características de determinada população ou o estabelecimento de relação entre elas.

\subsubsection{Análise Fatorial}

Como recurso analítico que construa um índice sintético do capital social para o conjunto de comunidades do município de Pentecoste utilizou-se a técnica de análise multivariada conhecida como análise fatorial. Esta fornece elementos para analisar a estrutura de inter-relações entre um grande número de variáveis, procurando descrevê-las através de um número menor de índices ou fatores (HAIR et al., 2009).

Conforme Fávero et al. (2009), o método de análise fatorial consiste na tentativa de se determinar as relações quantitativas entre as variáveis, 
aferindo seus padrões de movimento, de modo a associar àquelas um padrão semelhante, o efeito de um fator causal subjacente e específico a estas variáveis. representado por:

O modelo matemático simplificado da análise fatorial pode ser

$$
Z_{j=} \sum a_{j i} F_{i+} d_{j} u_{j}(j=1,2, \ldots, n) ;(i=1,2, \ldots, m)
$$

Tal que:

$Z_{j}=$ j-ésima variável padronizada;

$a_{j i}=$ é o coeficiente de saturação referente ao i-ésimo fator comum da j-ésima variável;

$F_{\bar{i}}=$ é o i-ésimo fator comum;

$d_{j}=$ é o coeficiente de saturação referente ao j-ésimo fator específico da jésima variável;

$u_{j}=$ é o j-ésimo fator específico da j-ésima variável.

De acordo com a análise fatorial, cada fator é constituído por uma combinação linear das variáveis originais inseridas no estudo. A associação entre fatores e variáveis se dá por meio das cargas fatoriais que podem ser positivos ou negativos, mas nunca superiores a um. Esses coeficientes de saturação têm função similar aos coeficientes de regressão na análise de regressão (SIMPLICIO, 1985).

Para aplicação dessa análise, foram selecionadas variáveis já apresentadas a respeito do capital social. Neste sentido, na análise fatorial a seleção das variáveis adequadas ao fenômeno que se deseja estudar é de extrema importância, pois uma vez a variável incluída na pesquisa tem implicações definitivas nos resultados.

O primeiro procedimento necessário é a verificação dos pressupostos que consistirá em analisar a normalidade da distribuição dos dados de cada variável. A distribuição desses dados de cada variável utilizará o Teorema do Limite Central, caso haja um grande número de variáveis aleatórias independentes e identicamente distribuídas, então a distribuição tenderá para uma distribuição normal, à medida que o número dessas variáveis aumenta indefinidamente, no caso específico, $n=56$. Além da estimação da matriz de correlação para checar a existência de relação entre as variáveis realizada por meio de testes de hipóteses específicos (GUJARATI, 2000).

A análise da matriz de correlação apresenta os coeficientes de correlação de Pearson para cada par de variáveis adotadas na pesquisa. A relação entre as variáveis será confirmada a partir do nível de significância dos coeficientes estimados ( $p$-value < 0,05). De acordo com Hair Jr. et al. (2005), a análise será iniciada com exame da matriz de correlações para verificação da existência de valores significativos que justifiquem a utilização da técnica. Ainda segundo os autores, se a visualização da matriz de correlações não mostrar um número substancial de valores maiores que 0,30 , haverá fortes indícios que a análise fatorial não ser adequada.

Conforme Fávero et al. (2009), verificar a adequabilidade dos dados para a análise fatorial é utilizado o índice Kaiser - Mayer - Olkin (KMO) em que varia de 0 a 1 e em que serve para comparar as magnitudes dos coeficientes 
de correlações observados com as magnitudes dos coeficientes de correlações parciais. Em relação a essa estatística, quanto menor o valor do respectivo teste, menor a relação entre as variáveis e os fatores, podendo o índice variar entre 0 e 1 .

O procedimento utilizado neste trabalho levou em consideração a extração dos fatores iniciais através da Análise dos Componentes Principais que mostrou uma combinação linear das variáveis observadas de forma de maximizar a variância total explicada. Para a rotação dos fatores utilizou-se o método Varimax, que é o mais utilizado e minimiza o número de variáveis com altas cargas em diferentes fatores permitindo a associação de uma variável a um único fator;

\subsubsection{Construção do Índice de Capital Social (ICS)}

O ICS das comunidades estudadas foi calculado a partir dos escores estimados que foram associados aos fatores obtidos na estrutura fatorial definida. Utilizou-se, adicionalmente, a raiz latente, ou o autovalor, que corresponde à soma (em coluna) das cargas fatoriais ao quadrado para 0 respectivo fator (HAIR et al., 2009, p. 101). A padronização dos escores fatoriais torna-se necessária de forma a enquadrá-los no intervalo de zero a um, a partir da expressão:

$$
F_{g J}^{*}=\frac{F_{g j}-F_{g F}}{F_{g F A}-F_{g F}}
$$

De modo que:

$F^{\star} g_{j}=$ escore fatorial do $g$-ésimo fator padronizado da j-ésima família; $(g=\{1, . ., 6\}$ e $\mathrm{j}=\{1, \ldots, 163\}$ )

$F g_{j}=$ escore fatorial do g-ésimo fator para da j-ésima família;

$F g F=$ menor escore fatorial do g-ésimo fator entre as família;

$F g F A$ = maior escore fatorial do g-ésimo fator entre as famílias das comunidades. equação:

Para a construção do ICS relativo a j-ésima família, definiu-se a

$$
I C S_{j}=\sum_{g=1}^{6} \frac{\gamma_{g}}{\sum \gamma} F_{g j}^{*}
$$

Em que $\mathrm{y}_{\mathrm{g}}$ corresponde ao autovalor do g-ésimo fator. Observa-se que a expressão $\gamma_{g} / \sum \gamma_{g}$ indica a participação relativa do fator $\mathrm{g}$ na explicação da variância total capturada pelos $\mathrm{n}$ fatores.

\subsubsection{Análise de Agrupamento ou Cluster}

Procedeu-se, ainda, à aplicação de outra técnica de estatística multivariada, a Análise de Agrupamento ou Cluster, a qual consiste na definição de grupos homogêneos e/ou heterogêneos, constituindo-se em um método orientador e norteador para identificação de diferenças de 
comportamento, tomada de decisões e definição de estratégias de atuação e planejamento.

O método adotado foi a Análise de Agrupamento Não Hierárquico (Técnica de Partição ou Agrupamento de k-médias), que é recurso comumente utilizado em estudos exploratórios descritivos, de modo a permitir uma classificação das comunidades rurais do município de acordo com a mensuração do capital social, tendo sido necessária a definição do número de agrupamentos. O método de k-médias é responsável por alocar cada um dos elementos existentes em um dos $\mathrm{k}$ grupos pré-definidos, objetivando minimizar a soma dos quadrados residuais dentro de cada grupo com a finalidade de aumentar a homogeneidade do mesmo (FÁVERO et al.,2009).

Consiste, portanto, em dividir um conjunto de elementos (famílias) em subconjuntos, os mais semelhantes possíveis, de modo que os elementos pertencentes a um mesmo grupo sejam similares com respeito às características que forem medidas em cada elemento. Ou seja, através de tal procedimento estatístico, os elementos são classificados em grupos restritos homogêneos internamente, com variabilidade intraclasse mínima e interclasse máxima (HAIR et al., 2009).

Os grupos foram divididos com base nos valores obtidos para o ICS a partir do índice fatorial, conforme definido anteriormente. Neste trabalho, as comunidades referentes ao município como um todo foram dividas em três clusters para as comunidades rurais do município de Pentecoste e dois clusters para o conjunto de comunidades da UAVRC.

\section{RESULTADOS E DISCUSSÕES}

\subsection{O Município de Pentecoste (CE)}

O município de Pentecoste possui uma área de $1.378,30 \mathrm{~km}^{2}$ e a maior parte do seu relevo encontra-se na depressão sertaneja. De acordo com dados do IBGE (2010), Pentecoste possui uma população de 35.400 habitantes, sendo 21.394 pertencentes à área urbana e 14.006 a área rural. Desses, 2.339 agricultores familiares fazem parte do público prioritário das políticas territoriais do Território citado, 324 famílias são assentadas e existem 367 pescadores.

Conforme Oliveira (2009), essa configuração demográfica, em que boa parte da população ainda encontra-se na zona rural, justifica-se pelo estímulo às atividades agrícolas na região. Suportada através das águas do reservatório Pentecoste, essa atividade, em sua maioria lavouras tradicionais de subsistência, desenvolveu-se ao longo dos canais do projeto de irrigação do Departamento Nacional de Obras Contra as Secas (DNOCS) e das margens do açude.

Segundo dados do IPECE (2013), os moradores de Pentecoste dispõem de 45 escolas públicas e duas particulares, o que repercute em uma boa taxa de escolarização, atingindo $86,46 \%$ para o ensino fundamental e $63,86 \%$ para o ensino médio. Em relação à saúde, o município possui 24 unidades de saúde, todas públicas, onde 277 profissionais da área atuam, a taxa de mortalidade infantil encontra-se em 15,07\%. Esse desenvolvimento é demonstrado pelo Índice de Desenvolvimento Humano Municipal (IDHM) do 
município que em 2000 era de 0,457 e em 2010 já se encontrava em 0,629. Com esse resultado, Pentecoste está em 82 lugar no ranking estadual (IBGE, 2010; IPECE, 2013).

\subsection{1. Índice de Capital Social (ICS) no Município de Pentecoste (CE)}

Com a aplicação da análise fatorial, obteve-se uma matriz de correlação com predominância de coeficientes superiores a 0,30 , indicando boa correlação entre as variáveis selecionadas no estudo, o que significa a possibilidade de aplicação da análise fatorial. Ainda como critério para aferir as intercorrelações na matriz de dados, a análise das Medidas de Adequação da Amostra revelam coeficientes superiores a 0,5. Os testes de adequabilidade da amostra revelam que os fatores encontrados se constituem em boas medidas de variabilidade dos dados originais. Com o KMO atingindo 0,680 pode-se afirmar que existe uma correlação média entre as variáveis e com o teste de esfericidade de Bartlett com nível de significância $(p$-value $=0,000)$ pode-se rejeitar a hipótese nula, ao nível de $1 \%$, de que a matriz de correlação é uma identidade, evidenciando, portanto, que há correlações entre as variáveis, tornando possível a aplicação da análise fatorial.

Após a rotação dos fatores pelo método varimax, o conjunto de 15 variáveis é representado por seis fatores, ou seja, com base na regra de retenção de fatores com valores maiores do que 1, foram retidos seis fatores que conseguem explicar $79,92 \%$ da variância dos dados originais, constituindose, portanto, em um bom nível de explicação, como explicitado na Tabela 1 (ver apêndice). A matriz de componentes também representada na tabela 1 apresenta cargas que correlacionam as variáveis aos fatores antes da rotação, permitindo verificar qual fator melhor explica cada uma das variáveis originais (FÁVERO et al., 2009).

Com a formação dos fatores, pode-se construir e calcular o ICS de cada comunidade rural do município e através do método de agrupamento ou cluster foi possível classificá-la em três clusters. O cluster com nível mais elevado de capital social (cluster 3) é composto por quatro comunidades do município de Pentecoste (Migua Terra, Malhada, Fazenda Lagoa Velha e Jardim), revelando um alto nível baseado nas respostas das famílias entrevistadas de acordo com as dimensões e variáveis apresentadas. O cluster por completo representa apenas $9,5 \%$ das comunidades rurais estudadas, explicitando a disparidade no nível do capital social quando se considera apenas 4 comunidades com o um ICS acima de 0,696 (Tabela 2).

O cluster com nível intermediário (cluster 1) é formado por 24 comunidades (57\%), demonstrando a realidade do município que apresentou um nível médio no geral (esse nível médio no geral foi determinado através da média de todos os índices calculados para as comunidades). Por fim, o cluster 2 , composto por 14 comunidades (33\%) é o que revela o nível mais baixo do capital social, ou seja, as comunidades pertencentes a esse grupo estão mais deficitárias no âmbito do capital social, necessitando de melhorias em todas as dimensões. A comunidade com o nível mais baixo é Coelho.

Observa-se uma forte assimetria nos níveis de capital social das comunidades rurais desse município obtendo três intervalos apresentados, sendo 0,732 o nível mais alto de capital social obtido e 0,393 o mais baixo. 
Como observou, aproximadamente, $57 \%$ das famílias rurais tem um nível médio do capital social, variando entre 0,566 e 0,579. A média dos índices por comunidade é 0,567 , confirmando essa afirmação (Tabela 2).

Tabela 2 - ICS do município de Pentecoste (CE)

\begin{tabular}{c|c|c|c}
\hline IDS & Intervalo & No Comunidades & $\begin{array}{c}\% \text { das } \\
\text { Comunidades } \\
\text { Estudadas }\end{array}$ \\
\hline Alto & $0,696 \mid--0,732$ & 4 & $9,5 \%$ \\
\hline Médio & $0,566 \mid--0,579$ & 24 & $57,2 \%$ \\
\hline Baixo & $0,393 \mid--0,467$ & 14 & $33,3 \%$ \\
\hline
\end{tabular}

Fonte: Resultados da Pesquisa.

De acordo com as variáveis estudadas para medir o nível do capital social, é perceptível que o município ainda tem muito que melhorar nesse âmbito. Apesar dos bons níveis em relação à segurança, aos problemas de diferenças, ao relacionamento com os vizinhos da comunidade onde residem e aos bons níveis de confiança em relação aos dirigentes da forma de organização na qual participa. Mas é necessário evoluir principalmente na criação de formas de organizações, acesso às políticas públicas focadas no desenvolvimento e assistência técnica agrícola, como apontam nas próximas seções.

A pesquisa de campo realizada demonstra que aproximadamente $78 \%$ das famílias entrevistadas participam de algum tipo de organização. Não obstante, essa resposta não é tão satisfatória quando se observa a demonstração de que cerca de $60 \%$ das famílias que responderam "sim" participam apenas da Associação Comunitária, 30\% participam do Sindicato dos Trabalhadores Rurais e da Associação ao mesmo tempo e $8 \%$ fazem parte apenas do Sindicato. É de suma importância a integração das famílias rurais na Associação da comunidade na qual fazem parte. Ainda, $60 \%$ das famílias costumam participar ativamente das reuniões da associação e sindicato em busca de melhorias, porém não se pode negar que há uma grande deficiência em relação a formas de organizações como grupos e cooperativas, tornando visível a falta de organização produtiva do meio rural do município.

Apesar da significativa participação das famílias na Associação Comunitária e da expressiva frequência das mesmas nas reuniões a fim de solicitar melhorias para a comunidade. Todavia, 51\% dos entrevistados responderam que não existe interação entre os moradores a fim de solicitar ações de desenvolvimento local para o meio em que vivem. Isso talvez seja um dos fatores para a falta de organização e melhorias nas comunidades.

No caso das políticas ou programas existentes no município focados na geração de desenvolvimento local, $62 \%$ das famílias dos agricultores entrevistados afirmaram existir algum tipo de política ou programa na comunidade onde residem e os mesmos participam de um ou vários deles. É necessário ressaltar que essas famílias só têm conhecimento das políticas ou programas na qual fazem parte. Por isso 38\% responderam não existir, pois os mesmos não participam de nada e não têm conhecimento ou não se interessam pelas políticas ou programas em ação. 
Conforme o Gráfico 1, as políticas ou programas mais presentes nas comunidades são o Programa 1 Milhão de Cisternas (P1MC), Programa Bolsa Família (PBF), Seguro Safra, Crediamigo, Agroamigo e PRONAF/Seca. Aproximadamente $25 \%$ dizem ter acesso ao P1MC e o PBF e $24 \%$ acessam somente ao $\mathrm{P} 1 \mathrm{MC}$, sendo essas políticas as mais presentes nas comunidades estudadas. O P1MC organizado pela ASA Brasil surgiu como uma proposta de convivência com a seca. O mesmo propunha a construção de cisternas de placa para o armazenamento de água da chuva para consumo humano, como demonstração de que tecnologias simples e baratas podiam ser elementos centrais de uma política de convivência com a seca (ASSIS, 2010).

Gráfico 1 - Políticas ou programas envolvidos na geração de desenvolvimento local nas comunidades do município de Pentecoste (CE)

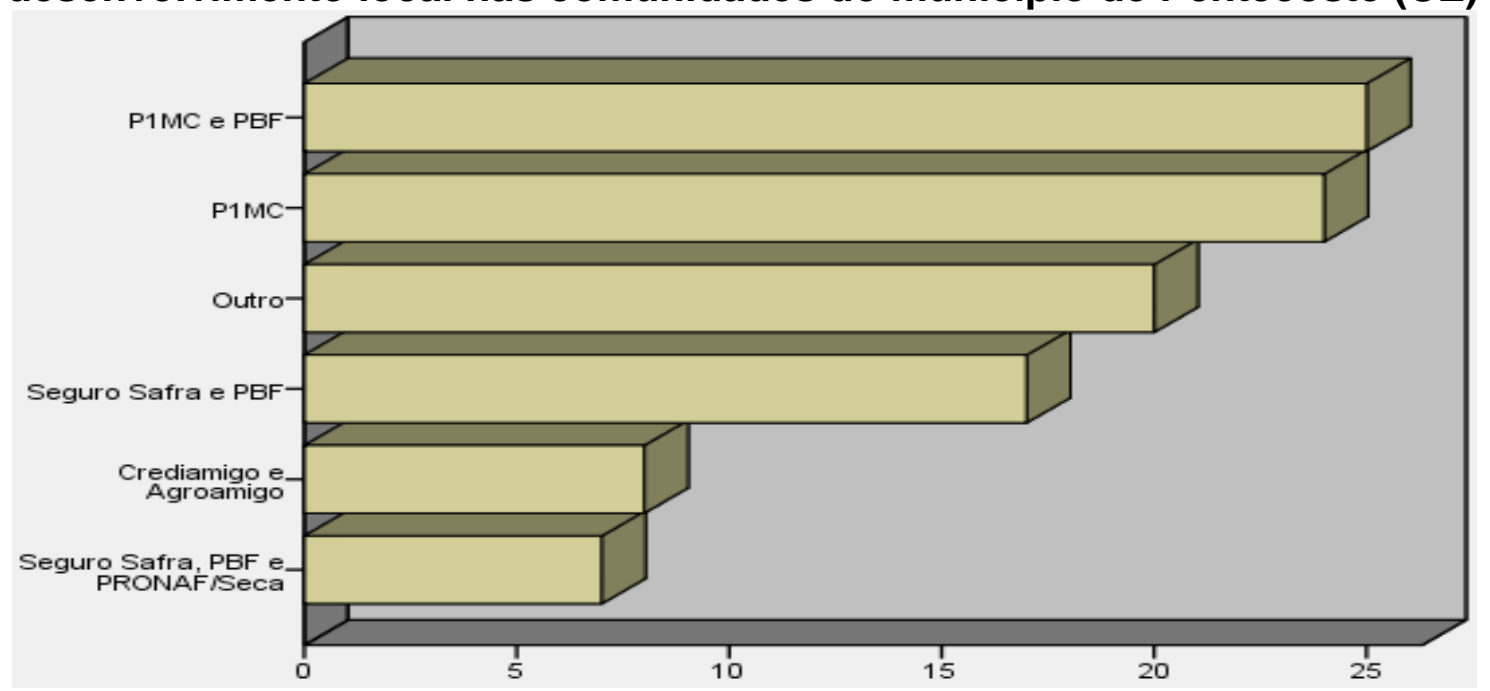

Fonte: Resultados da Pesquisa.

Em relação ao PBF, este se constitui na maior política de assistência do Brasil e foi criado em 2004, com a finalidade de unificar a gestão e a execução das ações de transferência de renda de outros programas preexistentes: Bolsa Escola, Bolsa Alimentação e Auxílio-Gás. Conforme Tavares (2010), atualmente, o PBF destina cerca de $R \$ 12$ bilhões ao atendimento de mais de 11 milhões de famílias. O Governo Federal visa assistir famílias em situação de pobreza e extrema pobreza, compostas por crianças com idade entre zero e quinze anos e/ou gestantes. Considera-se pobre ou extremamente pobre a unidade familiar cuja renda per capita mensal seja igual ou inferior a $R \$ 120,00$ e $R \$ 60,00$, respectivamente. O benefício varia de acordo com a renda e a composição familiar (TAVARES, 2010).

Essas duas políticas são as mais conhecidas entre as famílias das comunidades entrevistadas, pois em meio à realidade da seca vivida na região semiárida do Nordeste a construção de cisternas de placas é fundamental para a sobrevivência. O PBF também tem sido fundamental para a complementação da renda desses agricultores, uma vez que no ano agrícola 2014, período da aplicação da pesquisa de campo, a maioria não conseguiu manter suas plantações nem mesmo para o consumo da família, precisando assim de uma complementaridade da renda além de alguns auxílios necessários para cobrir custos das plantações perdidas. Já o Seguro Safra juntamente com o PBF teve 
aproximadamente $17 \%$ das respostas das famílias dos agricultores entrevistados. Como dito anteriormente, além do PBF para auxiliar na complementariedade da renda no período de escassez de água para a plantação e da falta de emprego, o Seguro Safra é de suma importância, pois ajuda a repor o capital perdido nas plantações não colhidas e criações mortas por falta de água e insumos.

Esse é um programa de seguro governamental criado em abril de 2002 e instituído como um benefício para garantir uma renda mínima aos agricultores familiares da região Nordeste em razão da seca e tem como gestor - MDA. Esse benefício é voltado para os agricultores familiares que perderam cerca de $60 \%$ da produção de algodão, milho, feijão e arroz (é devido a essa restrição que muitos dos entrevistados não puderam ter acesso ao seguro, pois obtiveram perdas durante o ano, mas de outros tipos de cultura) devido à ocorrência de estiagem comprovada. Os beneficiados devem possuir uma renda inferior a um salário mínimo e meio, área plantada de até dez hectares e não podem explorar área maior do que quatro módulos fiscais, independentemente do tipo de posse de terra. $O$ agricultor com produção irrigada não pode receber o benefício que é de $R \$ 600,00$ por família, realizado em até seis parcelas mensais (OZAKI, 2005).

Ainda sobre o gráfico 1 percebe-se que $8 \%$ das famílias estudadas já foram beneficiadas pelo Crediamigo e/ou Agroamigo, sendo esses uma forma de microcrédito que também atende agricultores familiares. Segundo as respostas dos indivíduos estudados, o acesso ao crédito é de suma importância para a construção e/ou reforma de benfeitorias nas unidades produtivas, compra de animais, sementes, insumos e materiais para ajudar na produção. Assim, pode-se dizer que esse número é baixo e precisa melhorar, dado a significância da ajuda. Conforme Neri \& Medrado (2006), o Crediamigo é um Programa de Microcrédito Produtivo e Orientado do Banco do Nordeste do Brasil (BNB). Este programa tem por objetivo oferecer crédito de maneira rápida e com pouca burocracia para microempreendedores das áreas atendidas pelo BNB. Ele começou a operar em abril de 1998 e atualmente é o maior programa de microcrédito de um banco público no Brasil.

Após o sucesso do Crediamigo, o BNB resolveu implantar o Agroamigo voltado exclusivamente para a concessão de crédito aos agricultores familiares. O crédito surgiu em 2005, e sua fonte de recursos provém do Fundo Constitucional de Financiamento do Nordeste (FNE). 0 Programa tem o objetivo geral de aumentar o atendimento aos agricultores familiares de pequeno porte, inicialmente beneficiários do PRONAF $B$, mediante a concessão de microcrédito produtivo e orientado. Apenas $8 \%$ das famílias rurais das comunidades estudadas em Pentecoste tem acesso a esses Programas de crédito. Isso porque grande parte não são organizadas em formas de organizações como grupos e cooperativas, cujas formas tornam mais fácil e viável a obtenção dos empréstimos. Essas pessoas reunidas em grupos e cooperativas quando investem em alguma atividade beneficiam todos da comunidade.

Em relação aos programas de crédito verifica-se o PRONAF/Seca que juntamente com o Seguro Safra e PBF têm $7 \%$ dos acessos. $O$ PRONAF/Seca é uma das categorias do PRONAF e foi criada em 2013 como uma forma emergencial através do BNB. O programa atendeu 2.676 famílias 
prejudicadas pela seca no Ceará. Os recursos foram destinados para construção de cacimbões, açudes, barragens subterrâneas, perfuração de poços, preparo de áreas no plantio de palma forrageira, capineiras, aquisição de equipamentos de irrigação para bombeamento de água até as residências de agricultores familiares, construção e recuperação de cercas, e também para compra de ração animal para os bovinos, caprinos, ovinos, suínos e aves (JORNAL DIÁRIO DO NORDESTE, 2013).

A presença do BNB com as políticas de crédito aos agricultores familiares foi de grande importância nos últimos anos em que se fez presente uma grande seca causando destruição no campo. Por fim, a respeito das políticas ou programas presentes nas comunidades do município em estudo, na categoria "outros" ficaram as marcadas por menos de 5\% das famílias de agricultores familiares entrevistados. Dentre elas estão: as políticas de comercialização Programa de Aquisição de Alimentos e Programa Nacional de Alimentação Escolar; Programa Sementes e Mudas; Programa Hora de Plantar e Previdência Social.

Vale ressaltar que apesar das questões terem sido a respeito de políticas ou programas envolvidos na geração de desenvolvimento local na comunidade onde a família reside, a maioria dos membros das comunidades só tem acesso a políticas assistenciais. Até mesmo as famílias que ficaram abaixo de $5 \%$, somente PAA e PNAE fazem parte da categoria perguntada. Apesar da categoria de políticas assistenciais serem de suma importância para esses agricultores ajudando-os a se reerguer em momentos de crise, elas não são geradoras de desenvolvimento. Em continuidade, são apresentadas as respostas sobre a Assistência Técnica para os indivíduos entrevistados, em que $65 \%$ afirmam obter algum tipo de assistência para a agricultura e $89 \%$ dos que responderam sim, afirmam receber assistência técnica da EMATERCE do município e 6\% de ONGs locais. A EMATERCE é uma empresa de Assistência Técnica e Extensão Rural do Estado do Ceará, fundada em 1954 sem fins lucrativos, vinculada à Secretaria de Desenvolvimento Agrário (SDA).

Dos entrevistados que responderam "sim", 30\% afirmaram que recebem essa assistência duas vezes por mês e $28 \%$ uma vez por mês, indicando que a assistência técnica não é um problema nas comunidades do município como um todo. Apesar de $35 \%$ ainda não terem acesso, a maioria que usufrui tem com frequência.

Assim, conforme as respostas obtidas pode-se considerar que 0 índice médio do capital social obtido anteriormente é válido. Apesar das boas relações de confiança e relacionamento, há uma deficiência principalmente quanto ao acesso e os tipos de políticas ou programas existentes. É ainda relevante ressaltar que o município possui um Indice de Desenvolvimento Humano (IDH) de 0,635, considerado baixo. Ou seja, é perceptível que essa é uma área de forte pobreza rural, demandante, portanto, de políticas públicas e com uma arena propícia para implantação de projetos de desenvolvimento local.

\section{CONSIDERAÇÕES FINAIS}

Esse trabalho buscou demonstrar o nível do capital social da agricultura em relação ao município de Pentecoste (CE). Com isso, utilizando a técnica de análise multivariada conhecida como análise fatorial construiu-se 0 
Índice do Capital Social para as comunidades rurais desse município. Adicionalmente, buscou-se identificar e classificar as comunidades em clusters, de acordo com a mensuração do capital social dessas comunidades através da análise multivariada de agrupamento ou cluster, agrupando os índices por comunidade em categorias de ordem baixa, média e alta.

O Índice do Capital Social para ambas as realidades se mostrou como médio, sugerindo uma carência nos padrões do capital social dos espaços estudados, que pode ser explicado por meio de análises de frequência de algumas questões presentes no banco de dados através das respostas obtidas na pesquisa de campo. Essas questões revelaram que há uma deficiência principalmente no âmbito das formas de organizações, na presença de instituições e de políticas voltadas para o desenvolvimento das comunidades. Ou seja, a maioria das políticas acessadas é de cunho assistencial e não abrange todas as famílias.

A respeito da assistência técnica, a mesma ainda não é atuante em todas as comunidades, porém já se apresenta de maneira significativa para várias famílias e também com certa frequência, sendo a EMATERCE o órgão mais atuante.

Como sugestão, vê-se a necessidade da busca de projetos, as organizações de ATER precisam incentivar e apoiar a criação de novas organizações nessas comunidades como grupos e cooperativas. A ampliação dos grupos já é existente e estes são de grande importância para a diversificação produtiva e geração de emprego em áreas rurais que sofrem com tais problemas. As Associações Comunitárias são formas positivas de organização e grande número de agricultores participa das mesmas em todas as comunidades. Elas podem ser utilizadas como um dispositivo para unir os moradores a fim de solicitar junto aos órgãos tanto a ampliação do número de beneficiários das políticas assistencialistas quanto a formação de políticas ou programas voltados ao desenvolvimento. Além de formações para 0 desenvolvimento das capacidades locais que venham de alguma forma melhorar a dinâmica desses locais de acordo com as demandas emanadas de diagnósticos comunitários.

A respeito do problema recorrente de escassez e falta de água, próprio das realidades semiáridas como a estudada, além do apoio ao P1MC, e sua segunda versão ampliada $\mathrm{P} 1+2$, que se revelou de ampla base para grande parte das famílias rurais entrevistadas, é preciso a articulação de órgãos públicos e da sociedade civil para conjuntamente apoiarem projetos de captação e armazenamento de água. Isso de forma descentralizada, da pequena irrigação e outras propostas tecnológicas produtivas de convivência com o semiárido em que se priorize o protagonismo dos sujeitos sociais e que favoreçam a eliminação ou redução de perdas da produção agropecuária em períodos de longa estiagem.

\section{REFERÊNCIAS}

ABRAMOVAY, Ricardo. Paradigmas do capitalismo agrário em questão. $2^{\text {a }}$ ed. São Paulo:editora Unicamp, 1998. 
,R.; BEDUSCHI FILHO, Luiz Carlos. Desafios para a gestão territorial do desenvolvimento sustentável no Brasil. In: XLI Congresso Brasileiro de Economia e Sociologia Rural (SOBER). Juiz de Fora, 2003.

ALBUQUERQUE, Gilton Carlos Anísio; CÂNDIDO, Gesinaldo Ataíde. Experiências de formação de capital social e políticas públicas de desenvolvimento territorial no Vale do Submédio São Francisco. Disponível em: <file:///C:/Users/usuario/Downloads/17-81-1-PB.pdf> Acesso em: 20 jun. 2014.

ALBAGLI, Sarita; MACIEL, Maria Lúcia. Capital Social e Empreendedorismo Local. Disponível em: $<$ http://www.ie.ufri.br/redesist/NTF2/NT\%20SaritaMLucia.PDF> Acesso em: 01 set. 2014.

ANDRADE, Elisabeth de Oliveira; CÂNDIDO, Gesinaldo Ataíde. A Relação entre os Níveis de Capital Social e os Índices de Desenvolvimento Sustentável: Uma Análise Comparativa entre Municípios. Disponível em: < http://www.anpad.org.br/admin/pdf/APS-C370.pdf> Acesso em: 02 ago. 2014.

ASSIS, Thiago Rodrigo de Paula. Sociedade civil e a construção de políticas públicas na região semiárida brasileira: o caso do programa um milhão de cisternas rurais (P1MC). Disponível em: <file:///C:/Users/Usuario/Downloads/1189-4213-1-PB.pdf>.Acesso em: 02 fev. 2015.

BARRETO, Ricardo Candéa Sá. Políticas públicas e o desenvolvimento rural sustentável no Estado do Ceará: estudo de caso. Dissertação (Mestrado em Economia Rural) - Universidade Federal do Ceará, Fortaleza, 2004.

BEDUCHI FILHO, Luiz Carlos; ABRAMOVAY, Ricardo. Desafios para o desenvolvimento das regiões rurais. Disponível em: $<$ http://www.abramovay.pro.br/artigos cientificos/2004/Beduschi Abramovay.p df. $>$ Acesso em: 25 jun. 2014.

DIÁRIO DO NORDESTE. Verba Emergencial do PRONAF Reduziu Impactos da Seca. Disponível em: $<$ http://diariodonordeste.verdesmares.com.br/cadernos/regional/verbaemergencial-do-pronaf-reduziu-impactos-da-seca-1.799446> Acesso em: 03 fev. 2015.

FÁVERO, L. P.; BELFIORE, P.; SILVA, F. L. da; CHAN, B. L. Análise de dados: Modelagem multivariada para tomada de decisões. Rio de Janeiro: Elsevier, 2009

GROOTAERT, C.; NARAYAN, D.; JONES, V. N.; WOOLCOCK, M. (2003). Questionário Integrado para Medir Capital Social. Grupo Temático sobre Capital Social. Washington, D.C.; World Bank. 
HAIR, F. Joseph; BLACK, William C.; BABIN, Barry J.; ANDERSON, Rolph E.; TATHAM, Ronald L. Análise multivariada de dados. Tradução Adonai Schlup Sant'Anna. 6. ed., Porto Alegre, Bookman, 2009.

INSTITUTO Brasileiro de Geografia e Estatística - IBGE. Censo Agropecuário1996 -2006. Disponível em: <www.ibge.gov.br>. Acesso em: 22 jun de 2014.

INCRA/FAO. Novo Retrato da Agricultura Familiar. O Brasil redescoberto. Brasília: Projeto de Cooperação Técnica INCRA/FAO, 2000 (FAO/BRA 036).

IPECE - Instituto de Pesquisa e Estratégia Econômica do Ceará. Perfil básico municipal 2013 de Pentecoste. Disponivel em: $<$ http://www.ipece.ce.gov.br/publicacoes/perfil basico/pbm-

2013/Pentecoste.pdf.> Acesso em: 20 jun. 2014.

LONG, Norman. Sociología del desarrollo: una perspectiva centrada en el actor. México, D. F: Centro de Investigaciones y Estudios Superiores en Antropologia Social, 2007.

NERI, Marcelo Côrtes; Medrado, André Luiz. Experimentando Microcrédito: Uma Análise de Impacto do Crediamigo no Acesso a Crédito. Disponível em: <http://www.cps.fgv.br/ibrecps/clippings/mc1037.pdf>. Acesso em: 02 fev. 2015.

OLIVEIRA, Rafael Reis Alencar. Estudo da qualidade ambiental do reservatório pentecoste por meio do índice de estado trófico modificado. Dissertação de Mestrado PRODEMA/UFC: Fortaleza, 2009, p.140.

OZAKI, Vitor Augusto. Métodos atuariais aplicados à determinação da taxa de prêmio de contratos de seguro agrícola: um estudo de caso. 2005. Programa de Pós Graduação em Economia. ESALQ/USP: Piracicaba, 2005.

SACHS, Ignacy; LAGES, Vinicius Nobre. Capital social e desenvolvimento: novidade para quem? Disponível em: < http://www.eclac.cl/prensa/noticias/comunicados/3/7903/sachsvinicius.pdf> Acesso em: 10 mar. 2014.

TAVARES, Priscilla Albuquerque Tavares. Efeito do Programa Bolsa Família sobre a oferta de trabalho das mães. Disponível em: <http://www.scielo.br/pdf/ecos/v19n3/08.pdf>. Acesso em: 02 fev. 2015.

ZANI, Felipe Barbosa. Gestão social do desenvolvimento: a exclusão dos representantes dos empresários? o caso do programa territórios da cidadania norte - RJ. 2010. Dissertação. FGV/ Escola Brasileira de Administração Pública e de Empresas: Rio de Janeiro, 2010. 


\section{APÊNDICE}

Tabela 1 - Composição dos fatores de acordo com as cargas fatoriais, variância explicada e comunalidades

\begin{tabular}{|c|c|c|c|c|c|c|c|}
\hline VARIÁVEL & 1 & 2 & 3 & 4 & 5 & 6 & COMUNALIDADES \\
\hline Participa de alguma forma de organização? & ,861 & ,366 & ,039 & ,005 &,- 108 & ,018 & $89 \%$ \\
\hline A forma de organização na qual participa é local ou regional? & ,882 & ,399 &, 016 &,- 058 &,- 057 &, 026 & $94,40 \%$ \\
\hline Participa com frequência da forma de organização que faz parte? & ,868 & ,310 &,- 012 &,- 095 &,- 066 & ,052 & $86,50 \%$ \\
\hline $\begin{array}{l}\text { Qual o nível de confiança em relação aos dirigentes da forma de } \\
\text { organização na qual participa? }\end{array}$ & ,861 & ,370 & ,037 &,- 007 &,- 059 & ,050 & $88,50 \%$ \\
\hline Qual o nível de confiança em relação aos governantes locais? & 204 &,- 324 &,- 186 &, 183 & ,310 &,- 099 & $51 \%$ \\
\hline $\begin{array}{l}\text { Qual o nível de relacionamento com os vizinhos da comunidade } \\
\text { onde reside? }\end{array}$ & ,035 &,- 253 & ,235 &,- 040 &,- 296 & ,604 & $57,50 \%$ \\
\hline $\begin{array}{l}\text { Participa de alguma atividade voluntária de cunho local ou } \\
\text { regional? }\end{array}$ & , 160 &,- 102 & ,017 &,- 160 & ,378 & ,714 & $71,50 \%$ \\
\hline $\begin{array}{l}\text { Existe interação na comunidade a fim de solicitar ações de } \\
\text { desenvolvimento local? }\end{array}$ &,- 436 & ,583 &,- 116 &, 573 & ,163 & ,205 & $94 \%$ \\
\hline $\begin{array}{l}\text { Participa das decisões a serem tomadas para o desenvolvimento } \\
\text { da comunidade? }\end{array}$ &,- 470 & ,638 &,- 087 & ,505 & ,032 & ,211 & $93,60 \%$ \\
\hline $\begin{array}{l}\text { Há problemas quanto as diferenças raciais, sociais, culturais, } \\
\text { políticas, religiosas na comunidade onde reside? }\end{array}$ &,- 196 & ,244 & ,898 &,- 065 & ,159 &,- 105 & $94,50 \%$ \\
\hline Alguns desses problemas já envolveram sua família? &,- 165 & ,189 & ,919 &,- 081 &, 171 &,- 080 & $95 \%$ \\
\hline Se sente seguro quanto à violência na comunidade onde reside? &,- 125 & ,039 & ,169 & ,315 &,- 740 &,- 077 & $69,80 \%$ \\
\hline $\begin{array}{l}\text { Verifica-se a presença de programas ou projetos envolvidos na } \\
\text { geração de desenvolvimento local na comunidade onde reside? }\end{array}$ &, 509 &,- 562 & ,270 & ,507 & ,069 & ,011 & $91 \%$ \\
\hline O senhor ou sua família participa de alguns desses programas? & ,496 &,- 573 & ,248 & ,516 &,- 014 & ,049 & $90,40 \%$ \\
\hline Possui assistência técnica para a agricultura? & ,419 & ,108 &,- 108 & ,265 & ,387 &,- 303 & $51,10 \%$ \\
\hline VARIÂNCIA EXPLICADA (\%) & $24,71 \%$ & $13,81 \%$ & $12,93 \%$ & $12,56 \%$ & $7,96 \%$ & $7,96 \%$ & $79,92 \%$ \\
\hline
\end{tabular}

Submetido em: 26/06/2015

Aceito em: 29/10/2015

Revista de Estudos Sociais \Ano 2015 N.34. V.17 